\title{
Upregulation of microRNA-370 promotes cell apoptosis and inhibits proliferation by targeting PTEN in human gastric cancer
}

\author{
YANG ZENG $^{1}$, MENG FU ${ }^{1}$, GANG-WEI WU ${ }^{1}$, AN-ZU ZHANG ${ }^{1}$, JIN-PING CHEN ${ }^{1}$, HONG-YUE LIN ${ }^{1}$, \\ YONG-AN FU ${ }^{1}$, JING JIA ${ }^{1}$, ZONG-DA CAI ${ }^{1}$, XIAO-JIAN WU ${ }^{2}$ and PING LAN ${ }^{2}$ \\ ${ }^{1}$ Department of General Surgery, The First Affiliated Quanzhou Hospital of Fujian Medical University, \\ Quanzhou, Fujian 362000; ${ }^{2}$ Department of Colorectal and Anal Surgery, The Sixth Affiliated \\ Hospital of Sun Yat-Sen University, Guangzhou, Guangdong 510000, P.R. China
}

Received May 16, 2016; Accepted July 6, 2016

DOI: $10.3892 /$ ijo.2016.3642

\begin{abstract}
Growing evidence suggests that microRNA plays an essential role in the development and metastasis of many tumors, including gastric cancer. Aberrant miR-370 expression has been indicated in tumor growth, but the mechanism of miR-370 inhibits both the proliferation and metastatic ability for gastric cancer remains unclear. Accumulating evidence reported that PTEN signaling pathway plays an important role in the cellular processes, such as apoptosis, cell growth and proliferation. The goal of this study was to identify whether miR-370 could inhibit the growth, migration, invasion, proliferation and metastasis of gastric cancer through targeting PTEN. Real-time PCR (RT-PCR) was used to quantify miR-370 expression in vitro experiments. The biological functions of miR-370 were determined via cell proliferation. Our study indicated that miR-370 targeted PTEN leading to activation of apoptosis signaling and the cell proliferation of cervical cancer cells, ameliorating gastric cancer growth and progression. In addition, the combination of miR-370 and PTEN inactivated AKT, MDM2 and mTOR while stimulated caspase-3, p53 and GSK $3 \beta$ expression, promoting apoptosis and suppressing proliferation of gastric cancer cells. Therefore, our study revealed the mechanistic links between miR-370 and PTEN in the pathogenesis of gastric cancer through modulation of cell apoptosis and proliferation. Additionally, targeting miR-370 could serve as a novel strategy for future gastric cancer therapy clinically.
\end{abstract}

Correspondence to: Dr Yang Zeng, Department of General Surgery, The First Affiliated Quanzhou Hospital of Fujian Medical University, Quanzhou, Fujian 362000, P.R. China

E-mail: zengyang362000@139.com; zy-better@163.com

Key words: gastric cancer, miR-370, proliferation, apoptosis

\section{Introduction}

Stomach cancer, also known as gastric cancer, develops from the lining of the stomach (1). The cancer may spread from the stomach to other parts of the body, especially the lungs, liver, bones, lining of the abdomen and lymph nodes (2). World-wide, stomach cancer is the fifth leading cause of cancer as well as the third leading cause of death from cancer making up 7\% of cases and $9 \%$ of deaths. Gastric cancer is a disease due to multiple factors $(3,4)$. Additionally, the pathogenesis of gastric cancer represents a classic example of gene-environment interactions (5). Cancer of the stomach is difficult to cure unless it is found at an early stage before it has begun to spread. Because early stomach cancer causes few symptoms, the disease is usually advanced when the diagnosis is made (6). Thus, finding effective target and strategy for therapies is necessary.

MicroRNAs (miRNAs) are endogenous, small 18-25 nucleotides, and non-coding RNAs that negatively regulate gene expression at the post-transcriptional level through binding to the 3'-untranslated region (UTR) belonging to a specific messenger RNAs (mRNAs) (7-9). With sequences partially complementary to their target mRNAs, miRNAs play critical roles in moderating (mostly suppressing) gene expression in a variety of organisms $(10,11)$. Moreover, studies have confirmed that miRNAs participate in various biological processes, including cell growth, development, proliferation and metabolism, via inhibition of mRNA translation $(12,13)$. Recently, studies revealed that $\sim 20-30 \%$ of human genes are regulated by miRNAs, affecting gene expression (14). miR-370 has been suggested to play an inhibition role in many cancers or tumors, including colon cancer and HCC, breast cancer as well as gastric cancer (15). Because modulation of miR-370 is common to a number of cancers, it has been hypothesized that miR-370 may play an essential role in tumor growth, development and tumorigenesis. However, the exact role of miR-370 on tumor progression remains unclear, especially in gastric cancer.

Previous studies indicated that miR-370 suppress solid tumor progression originated from cancer cell lines $(16,17)$. It is of interest that miR-370 might be a potential target for the inhibition of gastric cancer. However, there is not sufficient research on the role, effect, and significance of miR-370 at the clinical level in cervical cancer growth. Thus further study is 
required to confirm the effects of miR-370 in the inhibition of gastric cancer.

\section{Materials and methods}

Tissue specimens and cell cultures. Human gastric cancer and the adjacent normal non-tumor tissues were acquired from patients undergoing surgical resection in the Department of Gastric Cancer and Soft Tissue Sarcomas, Quanzhou Affiliated First Hospital of Fujian Medical University, Fujian, China, from January 2009 to December 2012 for quantitative RT-PCR analysis. All tissue samples were immediately frozen in the liquid nitrogen and then stored at $-80^{\circ} \mathrm{C}$ for the following studies.

Paraffin-embedded tumor tissues collected from consecutive patients with gastric cancer between January 2009 and December 2012 were performed for tissue assays. Clinical data collection and postoperative follow-up procedures were done based on a uniform guideline of the Fujian Cancer Center of Fujian Medical University. All samples were collected and analyzed with the prior written and informed consents, which were obtained from all patients, and the study was approved by the Clinical Research Ethics Committee.

Cell culture. Human gastric cancer cell lines, including NCI-N87, MKN74, NUGC-3, MGC-803 and BGC-823, and the normal gastric RGM-1 cells were purchased from American Type Culture Collection, the Cell Resource Center, Shanghai Institute of Biochemistry and Cell Bank at the Chinese Academy of Sciences. Cell lines were routinely authenticated by DNA-fingerprinting and isoenzyme analyses and checked for contamination by mycoplasma using Hoechst staining. All cell lines were maintained in Roswell Park Memorial Institute (RPMI)-1640, Dulbecco's modified Eagle's medium or minimum essential medium, containing $10 \%$ fetal bovine serum (FBS) and were incubated at $37^{\circ} \mathrm{C}$ with $5 \% \mathrm{CO}_{2}$.

Oligonucleotides. RNA oligos were synthesized chemically and purified by Genepharma Co. Ltd., (Shanghai, China). The sense sequence of human miR-370 mimics was 5'-GUG CCU GGG AGG CAC CAU AG-3' and antisense sequence was 5'-UGC UAG GUA GCC GUC CCU CCC A-3'. Negative control oligonucleotides was 5'-AAC AAG UCC UUG UGU ACT T-3' and 5'-GCA UGA AUT GUA AUU CGG T-3'. The final concentration of miRNA-370 was $50 \mathrm{nM}$.

Plasmids and transfection. The production of a miR-370 expression vector was carried out, a 235-bp genomic fragment which covers the region coding for pri-miR-370 and its upstream and downstream regions was PCR amplified and then cloned onto the pLvthm vector (Addgene, USA). The full length of PTEN-2 3'-UTR is 4,629 bp long. The miR-370 binding site in PTEN-2 3'-UTR is located at 4,335-4,344 bp. The region of the human PTEN-2 3'-UTR from 4,302 to 4,381 bp was generated by PCR amplification and subcloned into the sites of pGL3-basic luciferase reporter plasmid (Promega, USA). The miR-370 mimics, and negative control were purchased from Genecopoeia (Genecopoeia Co. Ltd., USA) and then transfected into gastric cancer cells with Lipofectamine 2000 reagent (Invitrogen, USA), based on the manufacturer's instructions.
Table I. The primary antibodies performed in western blotting.

\begin{tabular}{lll}
\hline Primary antibodies & $\begin{array}{c}\text { Dilution } \\
\text { ratio }\end{array}$ & \multicolumn{1}{c}{ Corporation } \\
\hline Rabbit anti-P53 & $1: 1,000$ & Cell Signaling Technology \\
Rabbit anti-MDM2 & $1: 1,000$ & Abcam \\
Rabbit anti-p-MDM2 & $1: 1,000$ & Abcam \\
Rabbit anti-mTOR & $1: 1,000$ & Abcam \\
Rabbit anti-p-mTOR & $1: 1,000$ & Abcam \\
Rabbit anti-p-GSK3 3 & $1: 1,000$ & Cell Signaling Technology \\
Mouse anti-PTEN & $1: 1,000$ & Abcam \\
Rabbit anti-caspase3 & $1: 1,000$ & Cell Signaling Technology \\
Rabbit anti-Bax & $1: 200$ & Santa Cruz Biotechnology \\
Rabbit anti-Bcl-2 & $1: 1,000$ & Cell Signaling Technology \\
Rabbit anti-AKT & $1: 1,000$ & Cell Signaling Technology \\
Rabbit anti-p-AKT & $1: 1,000$ & Cell Signaling Technology \\
GAPDH & $1: 500$ & Santa Cruz Biotechnology
\end{tabular}

Gene expression knockdown or inhibition of PTEN. PTEN expression in gastric cancer cells was silenced through transfecting the targeted siRNA sequences as follows (Sangon Biotech, China) with Lipofectamine 2000 (Invitrogen); AGA TAC GTT CTC TAC GCT CAG. The control siRNAs were produced through introducing 4 base substitutions in PTEN targeting sequence (GAG TCG GTA GCT ACA CTC). Fortyeight hours after transfection, PTEN expression was examined by immunoblotting.

Luciferase reporter assays. The gastric cancer cells, seeded in a 48-well plate, were co-transfected with $50 \mathrm{nM}$ single-stranded miRNA mimics, or negative control oligonucleotides, $50 \mathrm{ng}$ of firefly luciferase reporter and $10 \mathrm{ng}$ of pRL-TK (Promega) with the JetPRIME reagent. Cells were collected $36 \mathrm{~h}$ after the final transfection, and then analyzed via Dual-Luciferase Reporter Assay system (Promega).

Western blot analysis. Cell proteins were extracted using T-PER Tissue Protein Extraction Reagent kit (Thermo) according to the manufacturer's instructions. Protein concentrations were determined by BCA protein assay kit, and equal amounts of protein were loaded per well on a $10 \%$ sodium dodecyl sulphatepolyacrylamide gel. Subsequently, proteins were transferred onto polyvinylidene difluoride membrane. The resulting membrane was blocked with Tris-buffered saline containing $0.05 \%$ Tween-20 (TBS-T), supplemented with $5 \%$ skim milk (Sigma, USA) at room temperature for $2 \mathrm{~h}$ on a rotary shaker, and followed by TBS-T washing. The specific primary antibody, diluted in TBST, was incubated with the membrane at $4^{\circ} \mathrm{C}$ overnight. Subsequently, the membrane was washed with TBS-T followed by incubation with the peroxidase-conjugated secondary antibody at room temperature for $1 \mathrm{~h}$. The immunoactive proteins were detected by using an enhanced chemiluminescence western blotting detection kit. Western blot bands were observed using GE Healthcare ECL 
Western Blotting Analysis system and exposed to X-ray film (Kodak). The primary antibodies are shown in Table I.

$R N A$ isolation, reverse transcription $(R T)$ and real-time $P C R$ $(R T-P C R)$. Total RNA from tissue samples and cultured cells was isolated through the mirVana miRNA Isolation kit (Ambion) based on the manufacturer's instructions. Then the cDNA was synthesized from total RNA with the TaqMan miRNA reverse transcription kit (Applied Biosystems, USA). Real-time PCR was conducted using the Applied Biosystems 7500 Sequence Detection system with $\mathrm{iQ}^{\mathrm{TM}}$ SYBR Green Supermix (Bio-Rad Laboratories, USA) containing $5 \mathrm{ng}$ cDNA and $10 \mathrm{pM}$ of each primer. The data were normalized to the geometric mean of housekeeping gene GAPDH or U6 small nuclear RNA expression and calculated as $2^{-\triangle \Delta C T}$ method. Sequences of the primers are summarized as follows: miR-370 forward, 5'-GCA TCG TTC CTT CAA GCC GAT CT-3' and reverse, 5'-TGG GTG AGT CGT TCG G-3'; U6 forward, 5'-GTC CTG GCA GAT ATA CAC TAA ACA T-3' and reverse, 5'-CTC ACG CTT GAA TTC ATG CGG CTT-3'; PTEN forward, 5'-TGT TTG GCA GAT CTT CCT TG-3' and reverse, 5'-CTC GGT CGT CGC TCA TAT-3'; GAPDH forward, 5'-CAT TCA AGA CCG GAC AGA GG-3' and reverse, 5'-ACA TAC TCA GCA CCA GCA TCA CC-3'.

Cell proliferation analysis. The transfected gastric cancer cells were seeded into 96 -well plates at a density of $1 \times 10^{4}$ cells per well. Twenty microliters of $5 \mathrm{mg} / \mathrm{ml}$ MTT solution was administered to the cultures for a total volume of $200 \mu \mathrm{l}$ and then incubated for $4 \mathrm{~h}$ at $37^{\circ} \mathrm{C}$. After discarding the culture medium, the remaining crystals were then dissolved in DMSO. Finally, the absorbance of $560 \mathrm{~nm}$ was determined.

Colony-forming, migration and invasion assay. Gastric cancer cells were suspended in $0.9 \%$ methylcellulose-based semisolid medium MethoCult H4100 (StemCell, Beijing, China). After 14 days, individual primary clones ( 450 cells) were trypsinized and re-plated in the same conditions to examine the secondary colony-forming ability for self-renewal. For the Transwell migration assays, $10 \times 10^{4}$ cells were placed in the top chamber with a non-coated membrane. For the invasion assays, $2 \times 10^{5}$ cells were placed in the top chamber with a Matrigel-coated membrane. For both assays, the cells were seeded in a serum-free medium, and a medium with $10 \%$ serum was used as a chemoattractant in the lower chamber. The cells were then incubated for $16 \mathrm{~h}$ at $37^{\circ} \mathrm{C}$ and $5 \% \mathrm{CO}_{2}$ in a tissue culture incubator. After $16 \mathrm{~h}$, the non-migrated/ non-invading cells were removed from the upper sides of the Transwell membrane filter inserts with cotton-tip swabs. The migrated/invaded cells on the lower sides of the inserts were then stained with Giemsa, and finally the cells were counted.

Establishment of xenograft tumor models. The mouse experiments were conducted in the Animal Laboratory Center. NUGC-3 cells $\left(1 \times 10^{7}\right.$ cells) treated with miR-370 mimics were suspended in $100 \mu \mathrm{l}$ serum-free medium and injected subcutaneously into the left flank of 4- to 6-week old male BALB/c $\mathrm{nu} / \mathrm{nu}$ nude mice. Tumor size was measured with digital caliper and calculated every week. Tumor volume was measured every seven days and at the end of $\sim 6$ weeks after treatment, mice

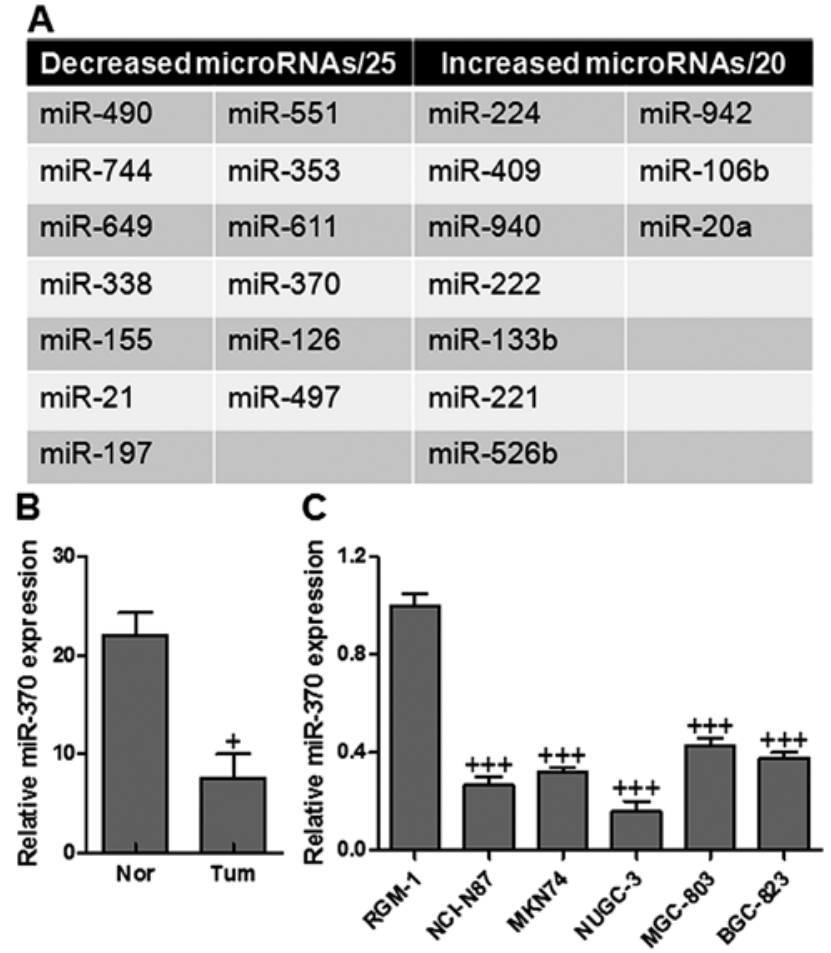

Figure 1. miR-370 is decreased in the tissues and cell lines of gastric cancer. (A) miRNAs expressed differentially in tissue samples of gastric cancer compared to adjacent normal samples. (B) Expression of miR-370 was measured in gastric cancer samples and normal tissues by RT-PCR. The expressed levels of miR-370 were normalized to U6 expression for the following analysis. (C) The expression levels of miR-370 were further tested in normal gastric cell line RGM-1 and gastric cancer cell lines of NCI-N87, MKN74, NUGC-3, MGC-803 and BGC-823 by RT-PCR, and the expression levels of miR-370 were normalized to U6 RNA expression for the following analyses. The values are presented as the mean \pm SD $(n=6)$ of the samples. ${ }^{+} \mathrm{p}<0.05$, ${ }^{++} \mathrm{p}<0.01$, and ${ }^{+++} \mathrm{p}<0.001$ versus the normal or RGM-1 groups.

were sacrificed. Tumors were excised, weighed, fixed in $10 \%$ neutral formalin, and embedded in paraffin for histological analysis.

Immunohistochemistry. The cells seeded on the plates were dewaxed and rehydrated with xylene and a graded alcohol series. Endogenous peroxidase activity was blocked with $3 \%$ hydrogen peroxide for $15 \mathrm{~min}$ at room temperature. After washing in water, non-specific binding sites were blocked with $5 \%$ bovine serum in phosphate-buffered saline (PBS) for $30 \mathrm{~min}$ at room temperature. The samples were incubated with primary monoclonal antibody PTEN, P53 and caspase-3 $(1: 200)$ at $4^{\circ} \mathrm{C}$ overnight. The slide was then gently rinsed with PBS and developed by the Envision system/HRP for $30 \mathrm{~min}$ and substrate-chromogen for $15 \mathrm{~min}$ at room temperature. The nuclei were counterstained with Mayer's hematoxylin.

Immunofluorescence assays. After induction by conditioned culture medium, the cells were fixed in $4 \%$ paraformaldehyde, permeabilized with $0.1 \%$ Triton X-100 in PBS containing $0.5 \%$ BSA (PBS-BSA) for $30 \mathrm{~min}$. The cells were subsequently incubated with PTEN for $30 \mathrm{~min}$, followed by labeling with Alexa Fluor 488-conjugated rabbit anti-mouse or goat anti-rabbit IgG antibody. The cells were viewed under a fluorescent microscope. 


\section{A PTEN (WT): 5'-AGCGAGGCUUCACCCAAUCTGCACGGCAGCGGGAAGG-3' | || || || miR-370: 3'-UAUGGAAUAAGUGGGCAUC-5' | || || | | PTEN (Mut): 5'-AGCGAGGCUUAGUUCAAUCTGCACGGCAGCGGGAAGG-3'}
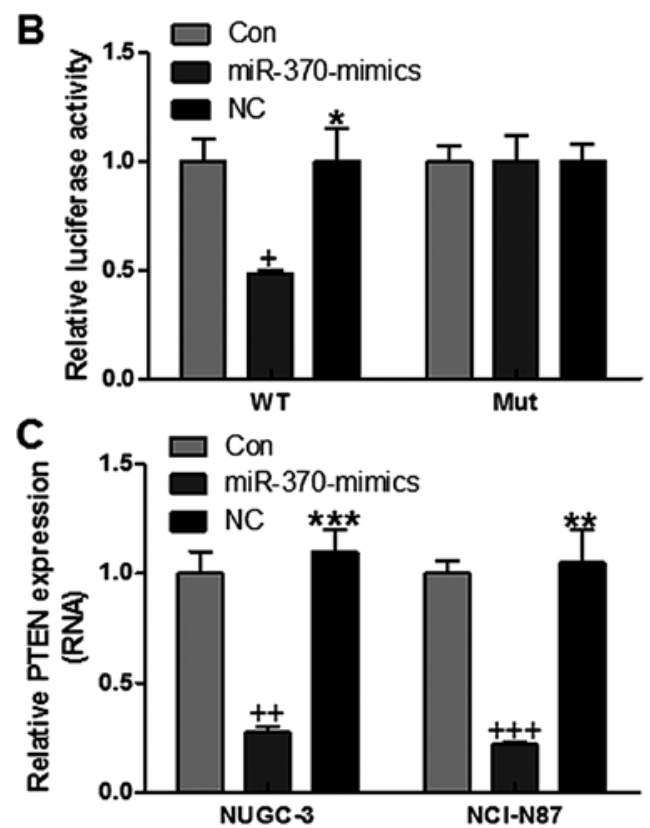
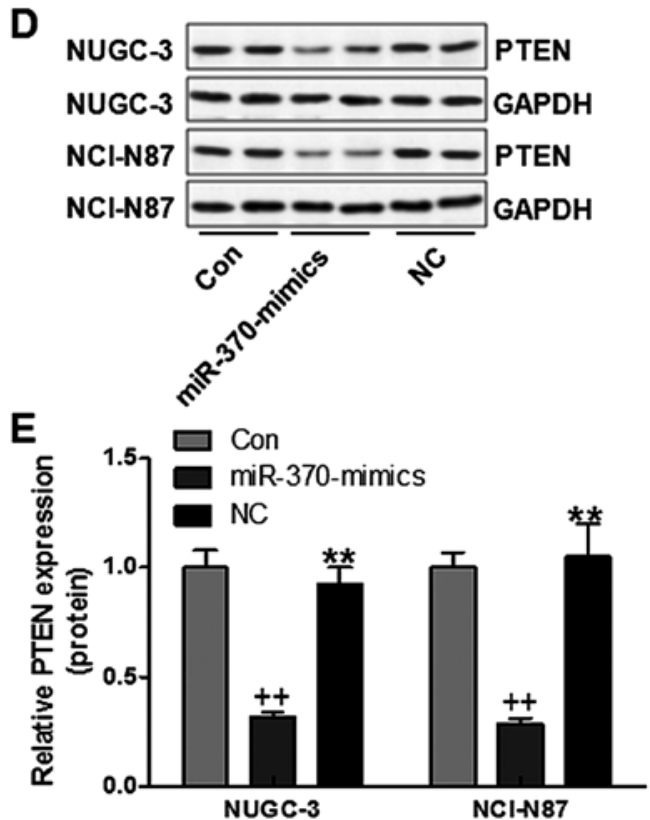

Figure 2. miR-370 directly targets and regulates PTEN expression in gastric cancer cells. (A) The wild-type (WT) and mutant (Mut) of putative miR-370 targeting sequences in PTEN mRNA. Mutant sequences are shown in bold type. (B) The measurement of luciferase activity in the NUGC-3 gastric cancer cells. (C) The effects of miR-370 mimics on the endogenous PTEN mRNA levels in NUGC-3 and NCI-N87 gastric cancer cells by RT-PCR analysis. The effects of miR-370 mimics on the endogenous PTEN protein levels in NUGC-3 (D and E) and NCI-N87 (D and E) gastric cancer cells by western blot analysis. The values are presented as the mean $\pm \mathrm{SD}(\mathrm{n}=6)$ of the samples. ${ }^{+} \mathrm{p}<0.05,{ }^{++} \mathrm{p}<0.01$, and ${ }^{+++} \mathrm{p}<0.001$ versus the control $(\mathrm{Con})$ group; ${ }^{*} \mathrm{p}<0.05,{ }^{* *} \mathrm{p}<0.01$, and **** $\mathrm{p}<0.001$ versus the miR-370-mimics group.

Flow cytometry assays. Flow cytometric assay was used to clarify the apoptotic cells and the cell cycle arrest. The gastric cancer cells were collected with trypsinisation and then washed twice with PBS, and fixed in cold $80 \%$ ethanol, and finally stored at $4^{\circ} \mathrm{C}$ overnight. The cells were washed with PBS twice and RNase A $(10 \mathrm{mg} / \mathrm{ml})$ was administered for analysis. Propidium iodide was then added to tubes at a concentration of $0.05 \mathrm{mg} / \mathrm{ml}$ and then incubated for $20 \mathrm{~min}$ at $4^{\circ} \mathrm{C}$ in the dark. FITC-labeled Annexin V/PI staining was applied based on the manufacturer's instructions (Keygen, China). In brief, $1 \times 10^{6}$ cells in each well were suspended with buffer containing FITC-conjugated Annexin V/PI. Samples were then analyzed by flow cytometry.

Statistical analysis. The differences of the data are presented as the means \pm SEM. The treated tissue and the corresponding controls were compared using Graph Pad Prism (version 6.0; Graph Pad Software, USA) by one-way ANOVA with Dunn's least significant difference tests. Differences between groups were considered significant at $\mathrm{p}<0.05$.

\section{Results}

miR-370 is decreased in the tissues and cell lines of gastric cancer. To be included in our analysis, the protein target of PTEN had to be predicted concordantly by at least three prediction tools and the following were used in our study: PicTar,
miRanda, TargetScan as well as miRDB. Based on the released version of January 2012, we found 8 microRNAs which potentially targeted PTEN. We explored several miRNAs expressed abnormally in gastric cancer with a gene chip (Fig. 1A). Based on the results of predictions above, miR-370 was an important upstream target of PTEN. To determine the expression levels of miR-370 in gastric cancer samples and cell lines, total RNAs were extracted from gastric cancer tissues and cell lines, and the expression levels of miR-370 were analyzed by RT-PCR and normalized to endogenous control (U6 RNA). As shown in Fig. 1B, miR-370 was significantly decreased in gastric cancer tissues in comparison with adjacent normal tissues. It was also shown that miR-370 was downregulated in gastric cancer cell lines, compared with normal gastric RGM-1 cells (Fig. 1C). The data suggested that miR-370 was decreased in the tissues and cell lines of gastric cancer.

miR-370 directly targets and regulates PTEN expression in gastric cancer cells. miRNAs mainly function via its regulation of target genes, and the target gene of miR-370 was further analyzed. After checking the newly published CLASH data, 408 genes were targeted by miR-370 in NUGC-3 cells. Among these genes, PTEN, a key regulator in apoptosis and proliferation, modulating cellular processes, was focused on in our study. In order to confirm whether miR-370 could affect the expression of PTEN, we performed luciferase reporter assays in NUGC-3 cells. We then created 

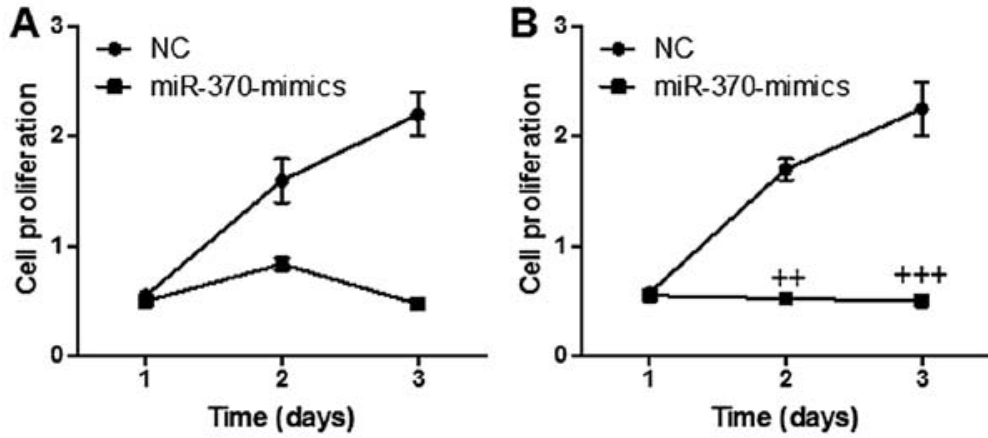

C

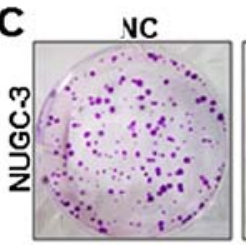

miR-370
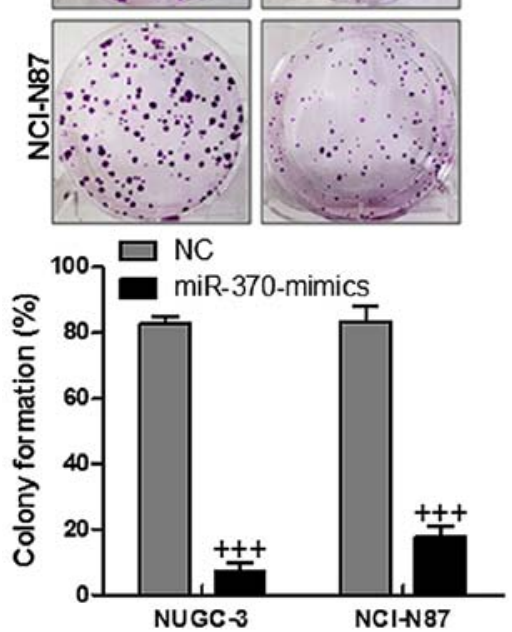

D
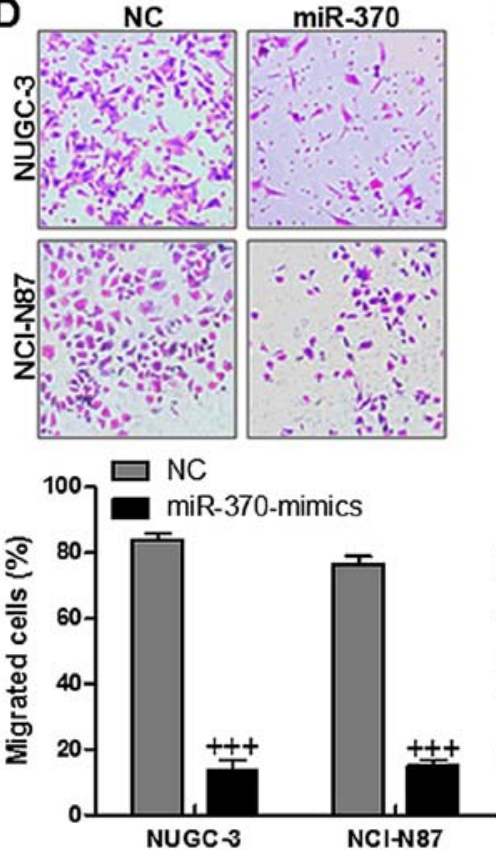

E

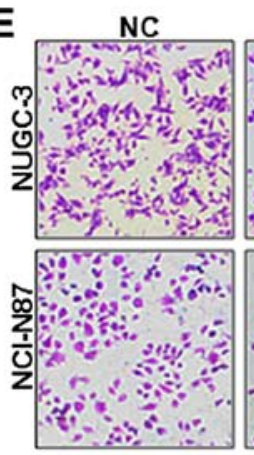

miR-370

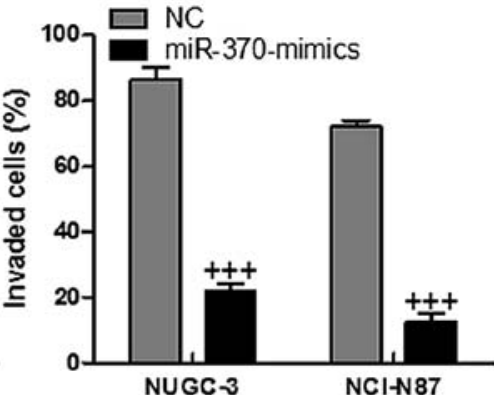

Figure 3. miR-370 downregulates gastric cancer cell growth and proliferation. Gastric cancer cell proliferation was significantly upregulated after Hsa-miR-370 infection compared with the negative control (NC) infection in (A) NUGC-3 and (B) NCI-N87. (C) miR-370 overexpression significantly enhanced the colonyforming ability of gastric cancer cell lines. (D) The representative images (up) and the quantification (down) of migrated gastric cancer cells across a Transwell chamber are shown in both cell lines. (E) The representative images (up) and the quantification (down) of the invaded gastric cancer cells across a Transwell chamber are shown in both cell lines. The values are presented as the mean \pm SD $(n=6)$ of the samples. ${ }^{+} p<0.05,{ }^{++} p<0.01$, and ${ }^{+++} p<0.001$ versus the control $($ Con) group.

a luciferase reporter plasmid with wild-type (WT) or mutant (Mut) targeting sequence of PTEN mRNA (Fig. 2A), which were cotransfected with miR-370 mimics or the negative control (NC) oligonucleotides into NUGC-3 cells for $48 \mathrm{~h}$, and determined luciferase activity in the transfected cancer cells. Our results indicated that the reporter plasmid with WT targeting sequence of PTEN mRNA caused a significant downregulation of luciferase activity in cells transfected with miR-370 compared with the control group without any treatment and negative group, whereas reporter plasmid with mutant sequence of PTEN produced no alteration of luciferase activity (Fig. 2B). NUGC-3 and NCI-N87 gastric cancer cells were transfected with miR-370 mimics, or negative control oligonucleotides, and PTEN mRNA and protein levels were examined by RT-PCR and western blot analysis, respectively. PTEN mRNA expression was low by miR-370 mimics in NUGC-3 and NCI-N87 cells, respectively (Fig. 2C). The level of PTEN protein was consistently and substantially downregulated by miR-370 in NUGC-3 gastric cancer cells, respectively (Fig. 2D and E). Also, similar expression levels were further confirmed in NCI-N87 gastric cancer cells (Fig. 2D and E). The results suggested that PTEN might be a direct target of miR-370 in gastric cancer cells.

miR-370 downregulates gastric cancer cell growth and proliferation. The gastric cancer cells with the enhanced miR-370 expression exhibited downregulated cell proliferation significantly in comparison to the cells of NC group in both NUGC-3 (Fig. 3A) and NCI-N87 cell lines (Fig. 3B). Cell function assays displayed that upregulation of miR-370 revealed lower number of colony formation in both NUGC-3 and NCI-N87 gastric cancer cell lines (Fig. 3C). In addition, impact of miR-370 on cell migration (Fig. 3D) and invasion (Fig. 3E) across a Transwell chamber showed that increasing of miR-370 ameliorated migration and invasion capacity of both gastric cancer cell lines, while upregulation of miR-370 inhibited migration and invasion capacity of both gastric cancer cell lines. In conclusion, the data suggested that miR-370 plays a potentially inhibiting role in gastric cancer growth and progression via the inhibition of cell proliferation, migration and invasion. 

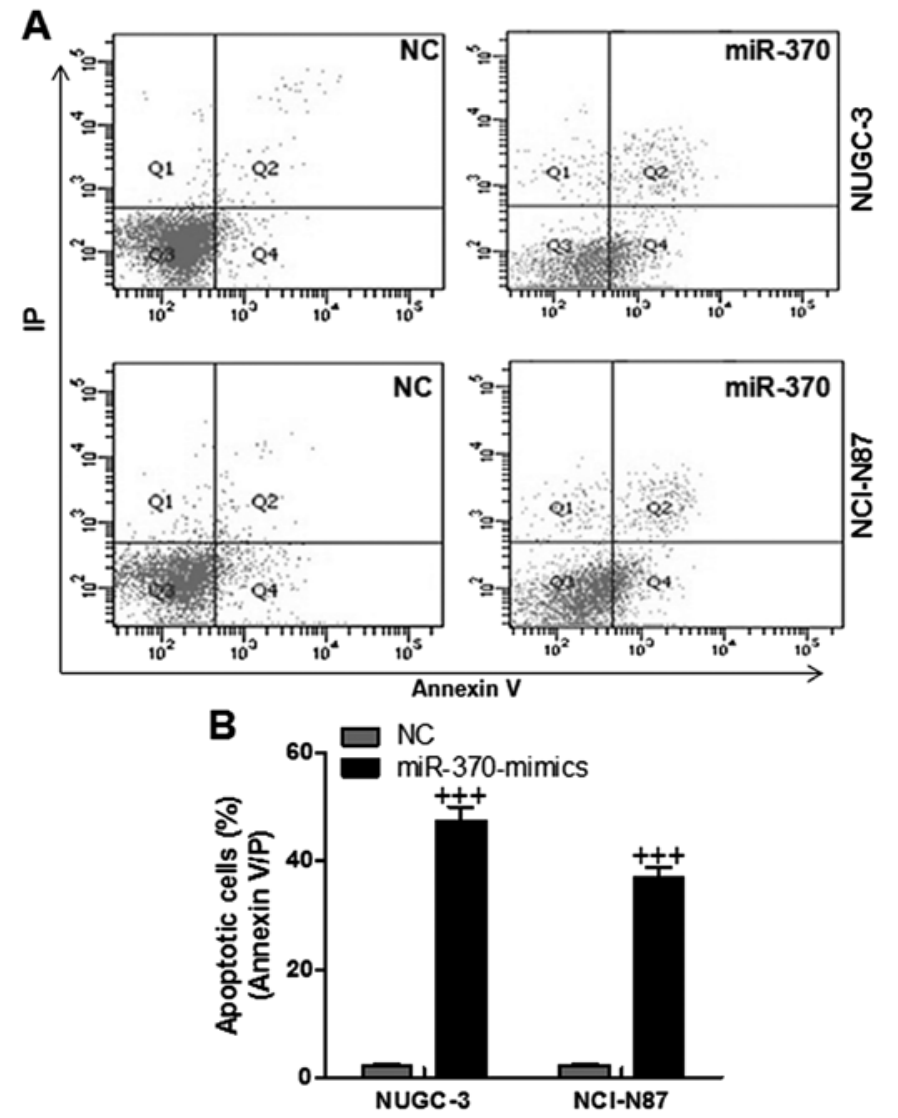

Figure 4. The effects of miR-370 on apoptosis in the gastric cancer cell lines via flow cytometry assays. (A) Flow cytometry was performed to determine the number of apoptotic cells in both NUGC-3 (up) and NCI-N87 (down) gastric cancer cell lines. (B) The calculation of apoptotic cells based on the results of flow cytometry. The values are presented as the mean $\pm \operatorname{SD}(n=6)$ of the samples. ${ }^{+} \mathrm{p}<0.05,{ }^{++} \mathrm{p}<0.01$, and ${ }^{+++} \mathrm{p}<0.001$ versus the control (Con) group.

The effects of miR-370 on apoptosis in the gastric cancer cell lines via flow cytometry assays. In order to further confirm that miR-370 could target PTEN, resulting in apoptosis in gastric cancer cells and ameliorating gastric cancer progression, flow cytometry was used to evaluate the apoptotic levels in NUGC-3 and NCI-N87 cells. As shown in Fig. 4, the number of apoptotic cells were higher in miR-370-mimic treated groups, indicating that miR-370 had a potential role in enhancing apoptosis in gastric cancer. We found that gastric cancer cell apoptosis was downregulated in cells transfected with miR-370 mimics with PTEN inhibition. However, the number of apoptotic cells was enhanced in the cells with forced miR-370 and PTEN restoration in both NUGC-3 and NCI-N87 cell lines (Fig. 5). The data indicated that miR-370 regulated apoptosis in gastric cancer cells via PTEN regulation.

The effects of miR-370 on cell cycle in the gastric cancer cell lines via flow cytometry assays. In order to determine if the reduction of cell growth in NUGC-3 and NCI-N87 cells regulated by miR-370 was linked with the alterations of cell cycle arrest, the gastric cancer cells were transfected with miR-370. Subsequently, flow cytometry was performed to determine the cell cycle. Our results showed that miR-370 mimics caused an increased population of G0/G1 and decreased population of S phase cells, suggesting that miR-370 had a potential ability to arrest the cervical cancer cell cycle in the G0/G1 and S phase (Fig. 6). No alteration was found in G2/M phase in the two groups in the gastric cancer cellss NUGC-3 and NCI-N87. Collectively, these data indicated that the inhibitory role of miR-370 on gastric cancer cell growth was related to induction of G0/G1 and S phase arrest.

miR-370 induces gastric cancer cell line apoptosis via $p$-AKT and Bcl-2 inactivation and caspase-3 activation. Loss of PTEN leads to the P13K/AKT signaling pathway to be hyperactive, resulting in cell survival and resistance to therapeutics in various cancers, including liver cancer (18). The Bcl-2 protein family includes major regulators of cell survival, including Bax, which promotes or suppresses apoptosis progression. Additionally, the caspase signaling pathway was partly regulated by Bcl-2 (19). The data above indicated that restoration of miR-370 could suppress the growth and proliferation of gastric cancer cells and PTEN might be a potential target of miR-370. So we hypothesized that miR-370 regulated cell growth in gastric cancer cells by targeting PTEN and its possible related signals. As expected, PTEN in NUGC-3 and NCI-N87 cells was reduced significantly (Fig. 7A-C). In addition, AKT was downregulated with Bcl-2 decreasing in cells with high level of miR-370. However, Bax was markedly activated, leading to the increasing of caspase-3 cleavage. Finally, apoptosis was enhanced due to caspase-3 activity. PTEN expression levels were determined via immunofluorescent assays. In NUGC-3 and NCI-N87 gastric cancer cells (Fig. 7D and E), PTEN was highly expressed in miR-370 mimic-treated group in comparison to the NC group. The data illustrated that miR-370 had a possible effect on accelerating apoptosis in gastric cancer cell growth and progression via caspase- 3 activation related with PTEN activation.

miR-370 regulates gastric cancer cell line proliferation and growth via 53 and mTOR signaling pathway through PTEN modulation. The murine double minute 2 (MDM2) protein is involved in the regulation of growth, survival, and invasion. p53, as an important tumor suppressor, was regulated by MDM2. MDM2/P53 signaling pathway plays an essential role in cell cycle arrest, regulating cell proliferation (20). Here we found that MDM2 was phosphorylated significantly in the NC group and miR-370 reduced this effect. Subsequently, p53 was upregulated, reaching the effect of gastric cancer cell growth (Fig. 8A). mTOR and GSK3 $\beta$ play important roles in cell growth translation and cell cycle. In our study, we found that mTOR was inhibited due to the high levels of miR-370 in both gastric cancer cells. While GSK3 $\beta$ was found to be enhanced in miR-370 mimics treatment (Fig. 8B). The data suggested that miR-370 could regulate gastric cancer cell proliferation and growth via MDM2 and mTOR inactivation and p53 and GSK3 $\beta$ activation. Next, PTEN was knocked down via siRNA treatment. As shown in Fig. 8C, PTEN was downregulated significantly in the NUGC-3 cells. Then the AKT, caspase-3, MDM2, mTOR and GSK3 $\beta$ signals were investigated. Fig. 8D shows that AKT activity was enhanced due to PTEN knockdown, resulting in Bcl-2 upregulation and Bax downregulation, and caspase-3 was reduced accordingly. PTEN knockdown promoted MDM2 phosphorylation and p53 decreased. In addition, mTOR was activated combined with 

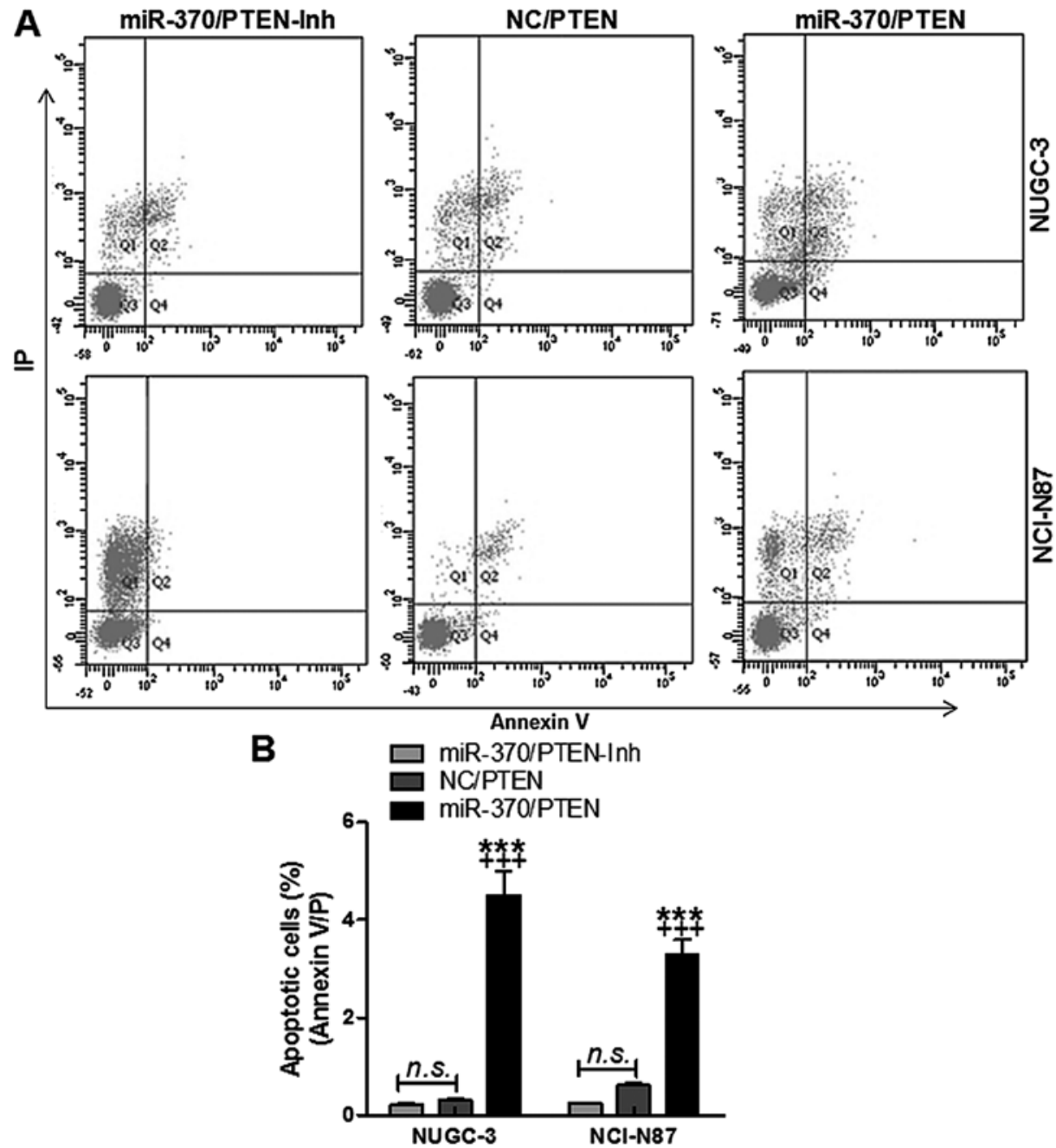

Figure 5. The effects of miR-370 on apoptosis in the gastric cancer cell lines through targeting PTEN. (A) Apoptosis of gastric cancer cells was restored after PTEN restoration. (B) The calculation of apoptotic cells based on the results of flow cytometry. The values present mean $\pm S D(n=6)$ of the samples. ${ }^{+} \mathrm{p}<0.05$, ${ }^{++} \mathrm{p}<0.01$, and ${ }^{+++} \mathrm{p}<0.001$ versus the miR-370/PTEN-Inh group; ${ }^{*} \mathrm{p}<0.05,{ }^{* *} \mathrm{p}<0.01$, and ${ }^{* * *} \mathrm{p}<0.001$ versus the NC/PTEN group.
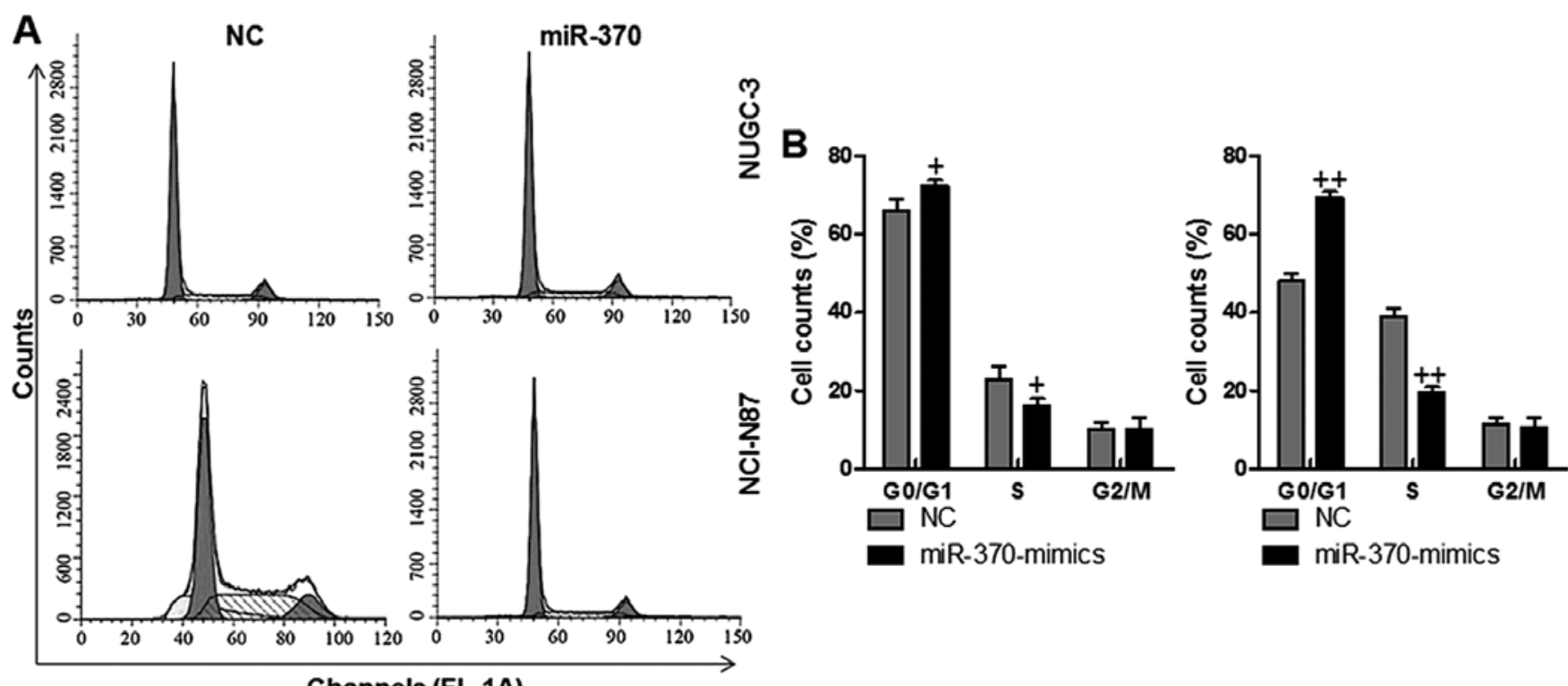

Channels (FL-1A)

Figure 6. The effects of miR-370 on the cell cycle in the gastric cancer cell lines in flow cytometry assays. (A) NUGC-3 (up) and NCI-N87 (down) gastric cancer cell lines were treated with or without miR-370-mimics, and flow cytometry was used to examine the number of NUGC-3 and NCI-N87 in different phases. (B) The histogram of percentage of NUGC-3 (left) and NCI-N87 (right) cells in different phases. The values are presented as the mean \pm SD (n=6) of the samples. ${ }^{+} \mathrm{p}<0.05,{ }^{++} \mathrm{p}<0.01$, and ${ }^{+++} \mathrm{p}<0.001$ versus the control (Con) group; ${ }^{*} \mathrm{p}<0.05,{ }^{* *} \mathrm{p}<0.01$, and ${ }^{* * *} \mathrm{p}<0.001$ versus the miR-370-mimics group. 


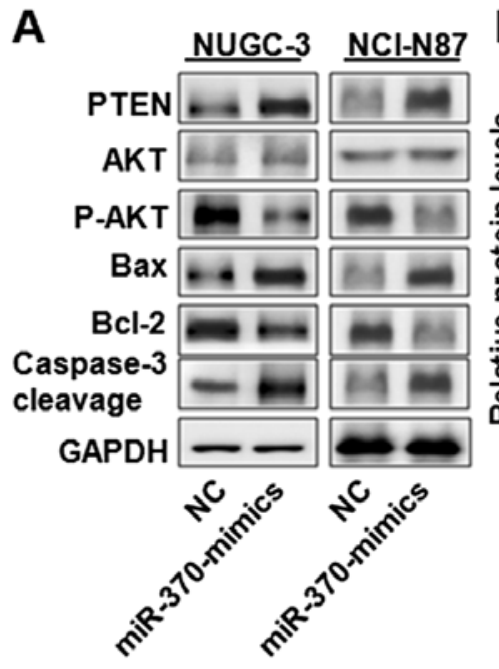

D
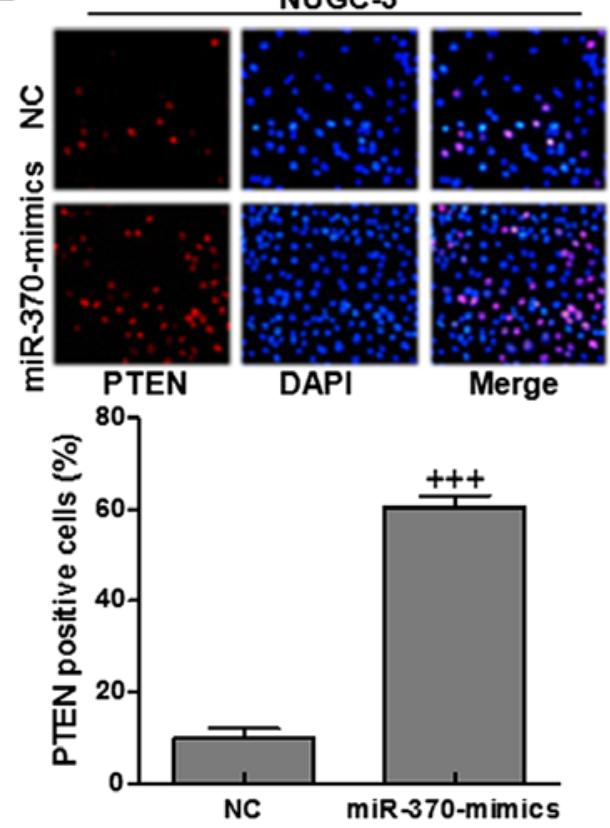

B $\square \mathrm{NC}$

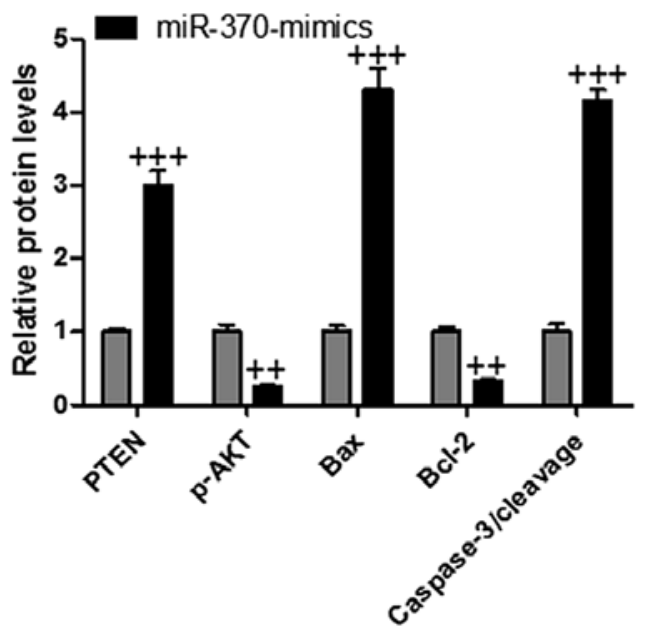

E

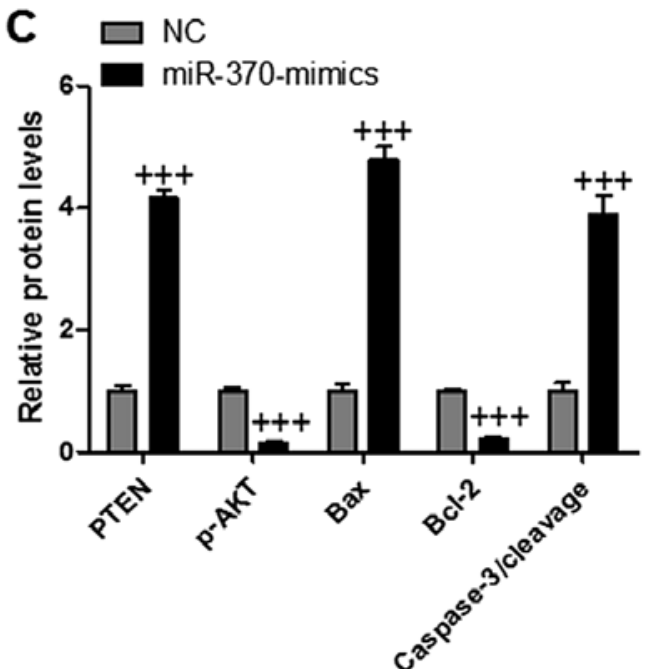

NCI-N87
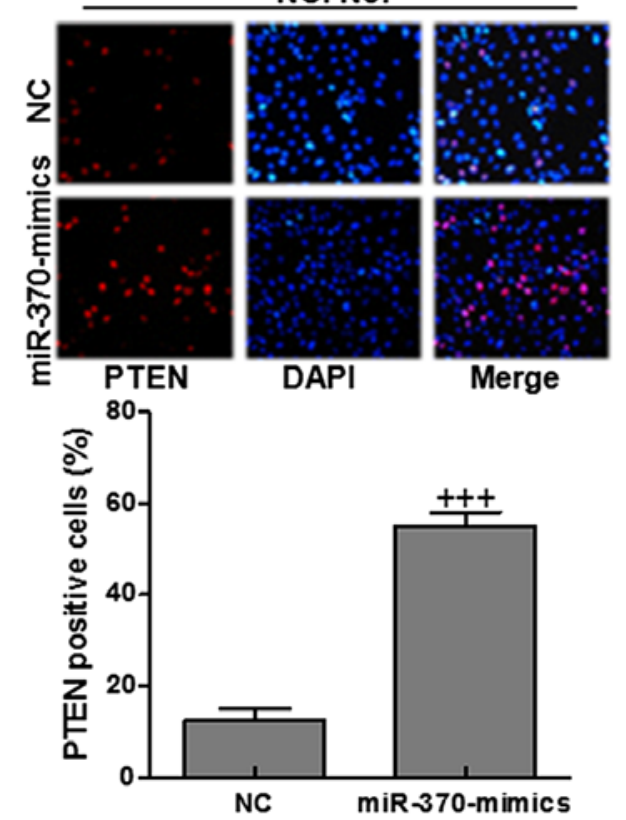

Figure 7. miR-370 induces gastric cancer cell lines apoptosis via p-AKT and Bcl-2 inactivation and caspase-3 activation. (A) miR-370 inhibited p-AKT and Bcl-2 expression while activating Bax and caspase-3 via western blot analysis in NUGC-3 (left) and NCI-N87 (right) cells. The histogram of percentage of protein levels of (B) NUGC-3 (left) and (C) NCI-N87 (right) cells. Immunofluorescent assays were used to calculate PTEN activity in (D) NUGC-3 (left) and (E) NCI-N87 (right) cells after miR-370 mimics treatment. The values are presented as the mean \pm SD $(n=6)$ of the samples. ${ }^{+} \mathrm{p}<0.05,{ }^{++} \mathrm{p}<0.01$, and ${ }^{++} \mathrm{p}<0.001$ versus the control (Con) group; ${ }^{*} \mathrm{p}<0.05,{ }^{* *} \mathrm{p}<0.01$, and ${ }^{* * * *} \mathrm{p}<0.001$ versus the miR-370-mimics group.

the upregulation of GSK3 $\beta$, further indicating that gastric cancer progression was, at least partly, related with PTEN expression levels (Fig. 8E). In order to further explore the effects of miR-370 and its target PTEN on gastric cancer cell growth, we combined miR-370 and PTEN-inhibitor together. As shown in Fig. 8F, we found that it was the combination of miR-370 and PTEN that had a significant role in reducing AKT activation and caspase- 3 promotion, leading to apoptosis in gastric cancer cells. Also, the combined miR-370 and PTEN could reduce p-MDM2 while increase p53 and GSK3 $\beta$ levels (Fig. 8G). The data further confirmed that PTEN was a direct target for miR-370-regulated gastric cancer development.

miR-370 inhibites tumor growth and progression in vitro. To understand whether miR-370 is involved in cervical cancer tumorgenesis in vivo, we engineered NUGC-3 cells to stably overexpress miR-370. The control cells, and miR-370-overexpressing cells were subcutaneously inoculated into nude mice, respectively. As shown in Fig. 9A and B, the tumors in the NC group grew more rapidly than the tumors in miR-370 group. Also, the tumor weight was higher in the NC group in comparison to the miR-370 group with significant difference (Fig. 9C). The results indicated that miR-370 could inhibit cervical cancer growth in vivo. Consistently, gastric cancer tissues with low miR-744 showed much lower expression of PTEN, P53 and caspase-3, compared with the normal gastric cancer tissues displaying high level of miR-370 (Fig. 9D). Taken together, the results demonstrated that PTEN might be a potential target of miR-370 in inhibiting gastric cancer cells in vivo. 

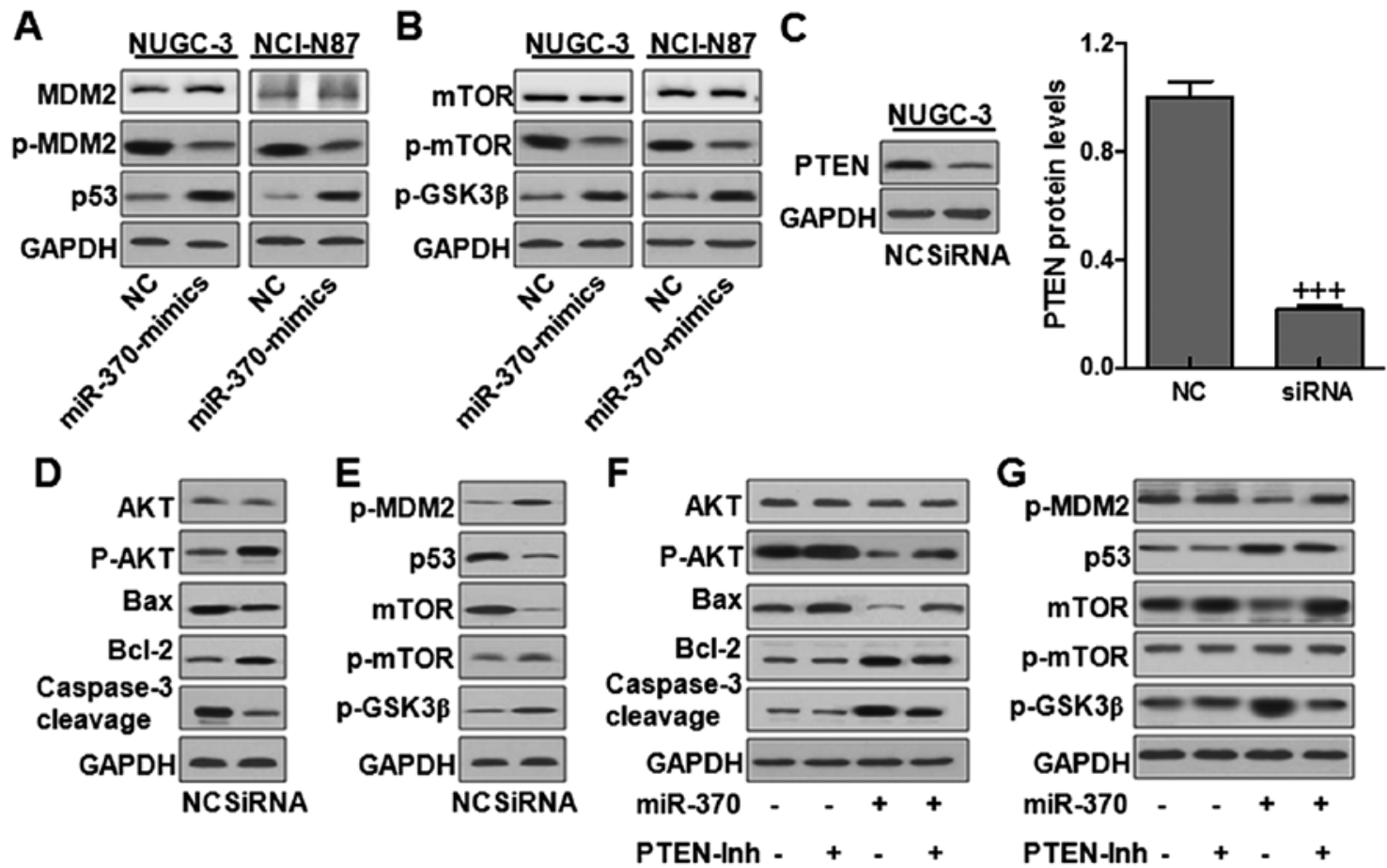

Figure 8. miR-370 regulates gastric cancer cell line proliferation and growth via p53 and mTOR signaling pathways through PTEN modulation. (A) miR-370 inhibited p-MDM2 expression while activating p53 activity via western blot analysis in NUGC-3 (left) and NCI-N87 (right) cells. (B) miR-370 inhibited p-mTOR expression while activating p-GSK3 $\beta$ in western blot analysis in NUGC-3 (left) and NCI-N87 (right) cells. (C) The protein levels of PTEN were evaluated with PTEN siRNA in NUGC-3 cells. (D) Western blot analysis was used to calculate AKT/Bcl-2 and caspase-3 signaling pathway after knockdown of PTEN. (E) The protein levels of p53 and mTOR/GSK3 $\beta$ were evaluated. (F) miR-370 inhibited AKT and Bcl-2 expression while activating caspase-3 through targeting PTEN in western blot analysis in NUGC-3 cells. (G) miR-370 inhibited p-MDM2 and p-mTOR expression while activating p53 and GSK3 3 activity through targeting PTEN via western blot analysis in NUGC-3 cells. The values are presented as the mean $\pm \mathrm{SD}(\mathrm{n}=6)$ of the samples. ${ }^{+++} \mathrm{p}<0.001$ versus the control (Con) group; ${ }^{*} \mathrm{p}<0.05,{ }^{* *} \mathrm{p}<0.01$, and ${ }^{* * *} \mathrm{p}<0.001$ versus the miR-370-mimics group.
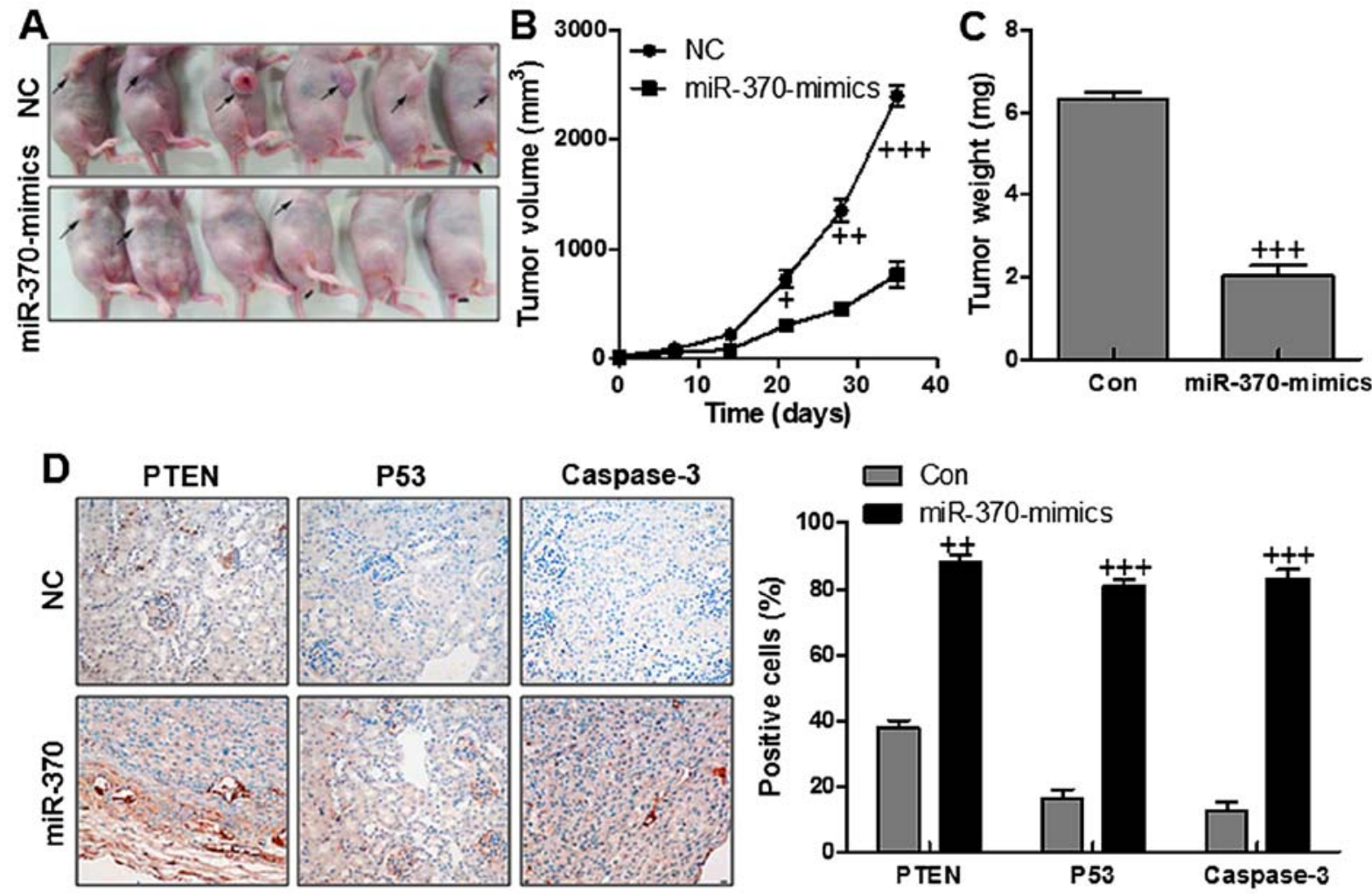

Figure 9. miR-370 inhibits tumor growth and progression in vitro. (A) Tumor xenograft model. The NUGC-3 cells were injected into the hind limbs of nude mice. (B) Tumor size and (C) weight were observed and measured. (D) Analysis of PTEN, P53 and caspase-3 expression in gastric cancer tissues by IHC. Brown signal in IHC was considered as positive staining for PTEN, P53 and caspase-3. The values are presented as the mean \pm SD ( $n=6$ ) of the samples. ${ }^{+} \mathrm{p}<0.05,{ }^{++} \mathrm{p}<0.01$, and ${ }^{+++} \mathrm{p}<0.001$ versus the control (Con) group; ${ }^{*} \mathrm{p}<0.05,{ }^{* *} \mathrm{p}<0.01$, and ${ }^{* * * *} \mathrm{p}<0.001$ versus the miR-370-mimics group. 


\section{Discussion}

Gastric cancer is one of the most frequent of all cancers world-wide (21). Most of the patients are diagnosed in the advanced stage and no more than one-half of these patients survive for over five years. Thus, searching for a more effective therapeutic strategy for detecting gastric cancer in early-stage is necessary for gastric cancer diagnosis and treatment (22). miRNAs are small non-coding RNAs, binding to sites in the 3'-untranslated region of targeting mRNAs (23), leading to mRNA degradation and translational repression (24). Previous studies have reported a number of miRNAs, which have essential effects on cancer progression, especially in the progression of tumor invasion as well as metastasis $(25,26)$. Downregulation of microRNA-370 has been suggested in various cancers. microRNA-370 can play as an oncogene or a tumor inhibitor gene. However, the clinicopathological importance of miR-370 expressed levels in gastric cancer has not been revealed. miR-370 expression was found to be frequently reduced in glioma tissues. In addition, its expression was negatively correlated with the malignant degree of many tumors. To our knowledge, miR-370 expression in gastric cancer has not been reported. This study was conducted to explore the miR-370 expression in gastric cancer tissues.

We reported that miR-370 was downregulated in gastric cancer tissues compared to the matched adjacent tissues of the tumor, and also the result was confirmed in gastric cancer cell lines. Decreased expression of miR-370 was related to clinicopathological features of gastric cancer significantly, including small tumor size, inhibition of cell migration, proliferation and invasion. Functionally, reduced expression of miR-370 promoted proliferation, colony formation as well as cell cycle progression in gastric cancer cells. Further, we found that PTEN was a novel direct target of miR-370. The functional role of miR-370 alteration in gastric cancer cells was related to PTEN. Furthermore, the PTEN expression was decreased in gastric cancer cells and its expression level was correlated with miR-370. Additionally, miR-370 was found to be related with G0/G1 and S phase arrest induction. Together, our results indicated that PTEN is a direct target of miR-370, which could inhibit gastric cancer development and progression.

$\mathrm{AKT}$ is a serine/threonine kinase-activated downstream of integrin (27). It is a receptor for different bioactive substances, pro-proliferation and the extracellular matrix receptor. AKT activation often results in tumorigenesis and plays an important role in cell motility regulation, which is essential for local invasion as well as metastasis. In the PTEN heterozygous knockout mice, PI3K/AKT signaling pathway is continually activated, contributing to tumor formation (28-30). Amplification and mutations of AKT gene lead to AKT activation in a variety of hematological neoplasms and solid carcinomas, and PTEN mutation has a negative effect on PI3K/AKT activation, causing the abnormal AKT activation (31). In our study, we found that PTEN was reduced significantly in gastric cancer cells with miR-370 downregulation. Then, abnormal AKT activation was caused, which was consistent with previous studies. The results here suggested that miR370-regulated PTEN alteration displayed regulation role in AKT activity. AKT regulates cancer cell proliferation by modulating $\mathrm{Bcl}-2$, Bax and caspase-3, which are linked to apoptosis. Studies have suggested that phosphorylated AKT could enhance Bcl-2 while suppressing Bax expression $(32,33)$. As an anti-apoptotic factor, Bcl-2 was found to be downregulated in gastric cancer cells with forced miR-370. In contrast, Bax as a pro-apoptotic factor was found to be enhanced after AKT inactivation induced by PTEN promotion with miR-370 enhancement. Of note, the cleaved caspase- 3 was discovered with high expression with PTEN and Bax increasing as well as p-AKT and Bcl-2 decreasing regulated by miR-370, which led to apoptosis in gastric cancer cells. The data above revealed that miR-370-targeted PTEN could inhibit gastric cancer progression and development via apoptosis promotion through inhibiting AKT and activating caspase-3.

Under normal physiological situations, P53, an important tumor suppressor gene, suppresses cell proliferation, inhibits cell division, and promotes the damaged DNA repair $(34,35)$. Also, p53 initiates apoptosis formation in case of failed DNA repair (36). In the absence of normal p53 protein, cells are known to be sensitive to the S phase entry with damaged DNA and the genetic alterations, leading to change of cell malignant and tumor formation (37). As a negative regulator of $\mathrm{p} 53$, $\mathrm{mdm} 2$ interacts with $\mathrm{p} 53$ protein to inhibit the transcriptional activation of $\mathrm{p} 53$, leading to cell proliferation in a tumor (38). In our study, we found that miR-370 could inhibit MDM2 activation, and subsequently, p53 was stimulated, performing its role in suppression of gastric cancer cell proliferation. The data in this regard illustrated that the miR-370-suppressed gastric cancer progression, at least partly was related to $\mathrm{p} 53$ activation and MDM2 inhibition.

mTOR is a serine/threonine kinase that is activated by AKT (39). The PI3K-AKT-mTOR pathway has been reported to be activated in many malignant tumors due to abnormalities in various genes. These fundamental findings suggest that the PI3K-AKT-mTOR pathway is important as a target for antineoplastic agents $(40,41)$. In our study, phosphorylated mTOR was found to be downregulated in gastric cancer cells with miR-370 enhancement. GSK $3 \beta$ was in contrast upregulated in the cells with high levels of miR-370, suppressing the cell cycle and growth.

In this study, we found that miR-370 could inhibit gastric cancer progression via targeting PTEN, which inactivated AKT. Subsequently, caspase-3 was enhanced, causing apoptosis. Further, p53 signaling pathway was stimulated due to increasing miR-370, displaying antitumor effects on gastric cancer. Also, mTOR inhibition as well as GSK $3 \beta$ promotion were discovered in gastric cancer cells expressing high level of miR-370. Of note, we found that it was the combination of miR-370 and PTEN that performed the role in gastric cancer suppression. Our results suggested that promoting miR-370 might be a therapeutic strategy in the gastric cancer treatment.

\section{References}

1. Karpińska-Kaczmarczyk K, Lewandowska M, Białek A, Ławniczak M and Urasińska E: Gastric hyperplastic polyps coexisting with early gastric cancers, adenoma and neuroendocrine cell hyperplasia. Pol J Pathol 67: 33-38, 2016.

2. Jung Y, Park J, Bang YJ and Kim TY: Gene silencing of TSPYL5 mediated by aberrant promoter methylation in gastric cancers. Lab Invest 88: 153-160, 2008.

3. Ushijima T and Sasako M: Focus on gastric cancer. Cancer Cell 5: 121-125, 2004. 
4. Smith MG, Hold GL, Tahara E and El-Omar EM: Cellular and molecular aspects of gastric cancer. World J Gastroenterol 12: 2979-2990, 2006.

5. Panani AD: Cytogenetic and molecular aspects of gastric cancer: Clinical implications. Cancer Lett 266: 99-115, 2008.

6. Maxwell AW, Wood S and Dupuy DE: Primary extraskeletal Ewing sarcoma of the stomach: A rare disease in an uncommon location. Clin Imaging 40: 843-845, 2016.

7. Iorio MV and Croce CM: MicroRNAs in cancer: Small molecules with a huge impact. J Clin Oncol 27: 5848-5856, 2009.

8. Hobert O: Gene regulation by transcription factors and microRNAs. Science 319: 1785-1786, 2008.

9. Glud M, Rossing M, Hother C, Holst L, Hastrup N, Nielsen FC, Gniadecki R and Drzewiecki KT: Downregulation of miR-125b in metastatic cutaneous malignant melanoma. Melanoma Res 20: 479-484, 2010.

10. Ueda T, Volinia S, Okumura H, Shimizu M, Taccioli C, Rossi S, Alder H, Liu CG, Oue N, Yasui W, et al: Relation between microRNA expression and progression and prognosis of gastric cancer: A microRNA expression analysis. Lancet Oncol 11: 136-146, 2010.

11. Croce C: Introduction to the role of microRNAs in cancer diagnosis, prognosis, and treatment. Cancer J 18: 213-214, 2012.

12. Nikitina EG, Urazova LN and Stegny VN: MicroRNAs and human cancer. Exp Oncol 34: 2-8, 2012.

13. Holley CL and Topkara VK: An introduction to small noncoding RNAs: miRNA and snoRNA. Cardiovasc Drugs Ther 25: 151-159, 2011.

14. Baroni D and Arrigo P: MicroRNA target and gene validation in viruses and bacteria. Methods Mol Biol 1107: 223-231, 2014

15. Sim J, Ahn H, Abdul R, Kim H, Yi KJ, Chung YM, Chung MS Paik SS, Song YS and Jang K: High MicroRNA-370 expression correlates with tumor progression and poor prognosis in breast cancer. J Breast Cancer 18: 323-328, 2015.

16. Duan N, Hu X, Yang X, Cheng H and Zhang W: MicroRNA-370 directly targets FOXM1 to inhibit cell growth and metastasis in osteosarcoma cells. Int J Clin Exp Pathol 8: 10250-10260, 2015.

17. Chen T, Gao F, Feng S, Yang T and Chen M: MicroRNA-370 inhibits the progression of non-small cell lung cancer by downregulating oncogene TRAF4. Oncol Rep 34: 461-468, 2015.

18. Cantley LC and Neel BG: New insights into tumor suppression: PTEN suppresses tumor formation by restraining the phosphoinositide 3-kinase/AKT pathway. Proc Natl Acad Sci USA 96: 4240-4245, 1999.

19. Yo YT, Shieh GS, Hsu KF, Wu CL and Shiau AL: Licorice and licochalcone-A induce autophagy in $\mathrm{LNCaP}$ prostate cancer cells by suppression of $\mathrm{Bcl}-2$ expression and the mTOR pathway. J Agric Food Chem 57: 8266-8273, 2009.

20. Lev Bar-Or R, Maya R, Segel LA, Alon U, Levine AJ and Oren M: Generation of oscillations by the p53-Mdm2 feedback loop: A theoretical and experimental study. Proc Natl Acad Sci USA 97: 11250-11255, 2000.

21. Yoshikawa T, Aoyama T, Tanabe K, Nishikawa K, Ito Y, Hayashi T, Cho H, Miyashita Y, Tsuburaya A and Sakamoto J: Feasibility and safety of transhiatal approach and D2 total gastrectomy after neoadjuvant chemotherapy for adenocarcinoma of the esophago-gastric junction: A subset analysis of the COMPASS trial. Dig Surg 33: 424-430, 2016.

22. Burkitt MD, Varro A and Pritchard DM: Importance of gastrin in the pathogenesis and treatment of gastric tumors. World J Gastroenterol 15: 1-16, 2009.

23. Kozomara A and Griffiths-Jones S: miRBase: Integrating microRNA annotation and deep-sequencing data. Nucleic Acids Res 39 (Database): D152-D157, 2011.
24. Wojcicka A, Swierniak M, Kornasiewicz O, W, Maciag M, Kolanowska M, Kotlarek M, Gornicka B, Koperski L, Niewinski G, et al: Next generation sequencing reveals microRNA isoforms in liver cirrhosis and hepatocellular carcinoma. Int J Biochem Cell Biol 53: 208-217, 2014.

25. Nielsen CB, Shomron N, Sandberg R, Hornstein E, Kitzman J and Burge CB: Determinants of targeting by endogenous and exogenous microRNAs and siRNAs. RNA 13: 1894-1910, 2007.

26. Jazdzewski K, Boguslawska J, Jendrzejewski J, Liyanarachchi S, Pachucki J, Wardyn KA, Nauman A and de la Chapelle A: Thyroid hormone receptor beta (THRB) is a major target gene for microRNAs deregulated in papillary thyroid carcinoma (PTC). J Clin Endocrinol Metab 96: E546-E553, 2011.

27. Courtney KD, Corcoran RB and Engelman JA: The PI3K pathway as drug target in human cancer. J Clin Oncol 28: $1075-1083,2010$

28. Song MS, Salmena L and Pandolfi PP: The functions and regulation of the PTEN tumour suppressor. Nat Rev Mol Cell Biol 13: 283-296, 2012.

29. Downes CP, Perera N, Ross S and Leslie NR: Substrate specificity and acute regulation of the tumour suppressor phosphatase, PTEN. Biochem Soc Symp 74: 69-80, 2007.

30. Kong D and Yamori T: Advances in development of phosphatidylinositol 3-kinase inhibitors. Curr Med Chem 16: 2839-2854, 2009.

31. Roy S, Yu Y, Padhye SB, Sarkar FH and Majumdar AP: Difluorinated-curcumin (CDF) restores PTEN expression in colon cancer cells by down-regulating miR-21. PLoS One 8: e68543, 2013.

32. Kunze D, Wuttig D, Fuessel S, Kraemer K, Kotzsch M, Meye A, Grimm MO, Hakenberg OW and Wirth MP: Multitarget siRNA inhibition of antiapoptotic genes (XIAP, BCL2, BCL-X(L)) in bladder cancer cells. Anticancer Res 28B: 2259-2263, 2008.

33. Wang YB, Qin J, Zheng XY, Bai Y, Yang K and Xie LP: Diallyl trisulfide induces Bcl-2 and caspase-3-dependent apoptosis via downregulation of Akt phosphorylation in human T24 bladder cancer cells. Phytomedicine 17: 363-368, 2010.

34. Bouska A, Lushnikova T, Plaza S and Eischen CM: Mdm2 promotes genetic instability and transformation independent of p53. Mol Cell Biol 28: 4862-4874, 2008

35. Clegg HV, Itahana K and Zhang Y: Unlocking the Mdm2-p53 loop: Ubiquitin is the key. Cell Cycle 7: 287-292, 2008.

36. Yamashita SI, Masuda Y, Yoshida N, Matsuzaki H, Kurizaki T, Haga Y, Ikei S, Miyawaki M, Kawano Y, Chujyo M, et al: p53AIP1 expression can be a prognostic marker in non-small cell lung cancer. Clin Oncol (R Coll Radiol) 20: 148-151, 2008.

37. Iwakuma T and Lozano G: MDM2, an introduction. Mol Cancer Res 1: 993-1000, 2003.

38. Günther T, Schneider-Stock R, Häckel C, Kasper HU, Pross M, Hackelsberger A, Lippert H and Roessner A: Mdm2 gene amplification in gastric cancer correlation with expression of $\mathrm{Mdm} 2$ protein and p53 alterations. Mod Pathol 13: 621-626, 2000.

39. Granville CA, Memmott RM, Gills JJ and Dennis PA Handicapping the race to develop inhibitors of the phosphoinositide 3-kinase/Akt/mammalian target of rapamycin pathway. Clin Cancer Res 12: 679-689, 2006.

40. Markman B, Atzori F, Pérez-García J, Tabernero J and Baselga J: Status of PI3K inhibition and biomarker development in cancer therapeutics. Ann Oncol 21: 683-691, 2010.

41. Karar J and Maity A: PI3K/AKT/mTOR pathway in angiogenesis. Front Mol Neurosci 4: 51, 2011. 